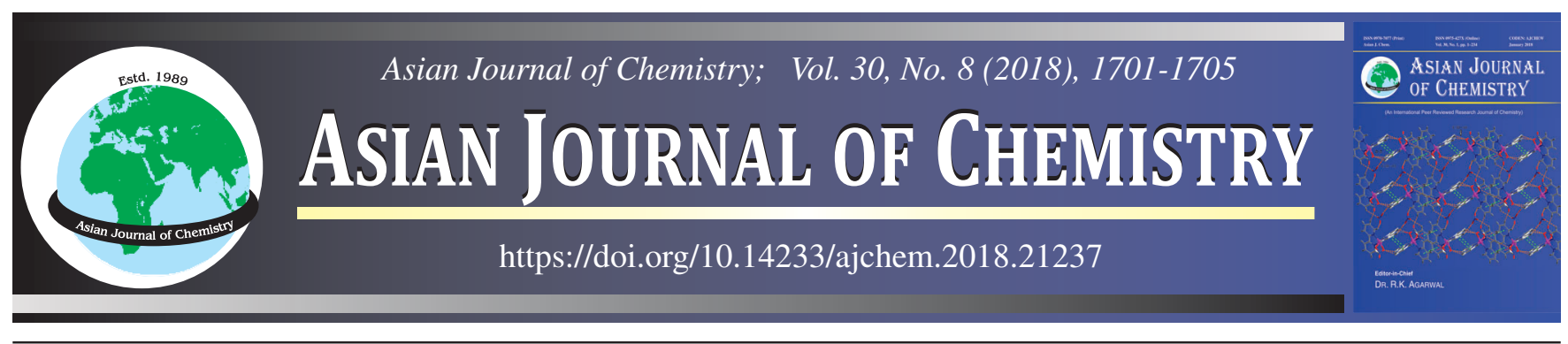

\title{
Determination of Diazinon and Carbofuran Residue Levels in Apples Kept in Cold Storage Depots in Karaman Province, Turkey
}

\author{
FevZi Kilicel ${ }^{1, *}$, Hacer Sibel Karapinar ${ }^{2}$ and Ihsan Serin $^{2}$
}

${ }^{1}$ Department of Chemistry, Faculty of Science, Karamanoglu Mehmetbey University, 70100 Karaman, Turkey

${ }^{2}$ Department of Chemistry, Institute of Science, Karamanoglu Mehmetbey University, 70100 Karaman, Turkey

*Corresponding author: E-mail: fevzi@kmu.edu.tr

Received: 18 January 2018;

Accepted: 14 March 2018;

Published online: 30 June 2018;

AJC-18959

\begin{abstract}
In this study, two pesticides viz., diazinon and carbofuran residue levels that is used in agricultural spraying in apple samples that were harvested in 2014 harvest season and kept in cold storage in Karaman province, were examined by gas chromatography-mass spectrometer (GC-MS) and gas chromatography-flame-ionisation detector (GC-FID) method. The samples that were taken from 6 different cold storages in the region at 5 different time zones, were kept in laboratory in refrigerator at $+4{ }^{\circ} \mathrm{C}$. The residue levels of diazinon and carbofuran pesticides in apple samples were determined. In order to identify pesticides residues at least three apple samples that were chosen randomly, were homogenized by homogenizator. In extract of samples QuEChERS method was used since it is fast, easy, lowcost, effective and reliable method. The residues of pesticides were taken from this homogenate with acetonitrile and given to GC-MS equipment in a suitable way. According to the results, carbofuran and diazinon pesticides types that are forbidden in Turkey, were determined in large amount of samples.
\end{abstract}

Keywords: Apple, Pesticides, Medicine residue, Carbofuran, Diazinon.

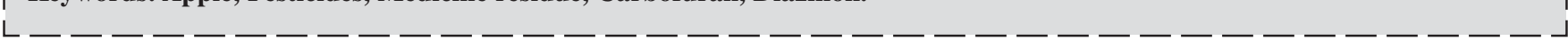

\section{INTRODUCTION}

Despite important benefits of pesticides in agricultural production, they are more or less toxic compounds and consuming of food having pesticides residue over permitted level, forms risk on human health [1,2]. Pesticides involve all chemicals that are classified as insecticide (insect killer), herbicide (weed destroyer), rodenticide (rodent killer) etc. [3]. Pesticides with chemical and biological variation products (metabolites) attract attention not only with their biocide effects but also with their targets and effects in total ecosystem. There are more than 10000 insects, 600 weeds, more than 1500 plant disease and 1500 type nematods that can be harmful to people, animals and plants at various levels [4]. Pesticites or pesticites derivatives on or in the product are called "pesticides residue". The limit of this residue that does not form a risk in terms of human and animal health is generally defined as maximum residue limit (tolerance, MRL) [5]. Do not using agricultural pesticides at exact dose or on time affects human and environmantal health negatively. Measuring of residue levels of active materials becomes important in Turkey as it is in all over the World since they are toxic, mutagenic, carcinogenic and teratogenic in terms of human and environmetal health. Apart from accidents the harm for human comes out in stages such as transportation, storage, using and comsumption of food involving pesticides residues. According to the U.S. Environmental Protection Agency, pesticides have been linked to developmental problems in children [6] and may act as carcinogens or negatively affect the endocrine system. Pesticides can be roughly classified as hydrophilic (water soluble) or hydrophobic (water insoluble). It is well known that the soluble pollutants on the surface of products are easily washed off with water, whereas insoluble pollutants persist on food and potentially threaten human health. In addition to insoluble surface pesticides, pesticide residues that are physically inside food products also persist after washing. Numerous studies have reported that food processing (including washing, peeling, boiling and juicing) can largely reduce the levels of pesticide residues in food [6-8]. Many studies have been carried out on the removal of pesticide residues from apples during home preparation and commercial processing [8-11]. Fruit and vegetable compounds that pesticides are applied and their shell life change according to pesticides group, climatic conditions, their formulation forms and structure of fruits and vegetables. Generally the compounds of organic phosphoric pesticides spoil or clear away in short time without leaving residue. On the other hand, organic chloride pesticides stay long on fruit and vegetable. That is why organic chloric pesticides are not preferred in 
usage. As pesticites usage changes between $1.2-13.8 \mathrm{~kg} / \mathrm{ha}$ in European Union countries, it is between $490-700 \mathrm{~g} / \mathrm{ha}$ in Turkey $[12,13]$. These values show that Turkey use rather low level of pesticides according to European Union countries. However according to residue analysis results conducted in Turkey although very few risky product number in terms of pesticides residue are reported, according to EU Fast Alarm System results the existence of pesticides residue on products sent from Turkey to EU is spectacular. As the number of party is 141 in products exported to EU countries in 2001, they increased to 202 in 2003 [13]. Pesticides left on soil after plant and soil applications can reach under ground water and other water sources with rain water as runoff or flow down. Carried pesticides due to slope, vegetation, formulation, soil type and rainfall cause the death of fish and other invertebrate water organisms in these waters. The pesticides residues in these organisms enter food chain of people as well as chronic toxicity by consumption of these contaminated waters. Since pesticides lose their effects in short time after their usage, disinfection is needed again. When this process is repeated one or twice, it leaves a little residue on product. Pesticides show toxicity by making cumulation in body. When they are taken to body they are spoiled by the effect of enzyms and some part of it is discarded from body [14]. Poisoning in human happens by taking pesticides to body via skin, respiration or digestion. When exposed to pesticides for a long time, some defaults happen in nervous, respiration, cardiac, vein, stomach, digestion and circuit systems, in inner organs such as liver, kidney etc., skin and eyes. Also it has got serious effects such as cancer, tumour, irritation and wounds on skin, preventing recovery of wounds and cell renewal, deterioration of immune system and causing mutation by causing DNA failure in cells. According to Turkish Food Codex (TGK) pesticides maximum residue regulation dated 25 August 2014, its usage in Turkey was banned [15]. According to 2011 TGK regulation MRL values of carbofuran diazinon are given in Table-1 [16]. According to 2013 TGK regulation pesticides the carbofuran and diazinon usage was banned, are placed in pesticides list.

\section{TABLE-1}

MAXIMUM RESIDUE LIMIT VALUES OF PESTICIDES $(\mathrm{mg} / \mathrm{kg})$ (REGULATION OF MAXIMUM RESIDUE LIMITS OF TGK PESTICIDES, 2011) [Ref. 16]

\begin{tabular}{ccc}
\hline Pesticides & MRL value & Explanation \\
\hline Carbofuran & $0.02^{*}$ & Prohibited Pesticide \\
Diazinon & $0.01^{*}$ & Prohibited Pesticide \\
\hline
\end{tabular}

*The lowest analytically detectable limit

For pesticide residue analysis in different kind of matrices, liquid chromatography (LC) and gas chromatography (GC) are commonly used. Gas chromatography, coupled to different detectors, is used for the analysis of volatile and semi-volatile pesticides. However, the mass spectrometer detector is the most widely used due to its high selectivity and sensitivity and capability to detect compounds with different chemicals [17-19].

Over the last 40 years, various methods have been developed to investigate multiresidues of pesticides in food, given the variety of products applied to crops. In the QuEChERS method (quick, easy, cheap, effective, rugged and safe) samples are extracted with acetonitrile, magnesium sulfate and sodium chloride, followed by clean-up using dispersive solid-phase extraction with primary and secondary amine [20,21]. Gas or liquid chromatography coupled with mass spectrometry is normally used to quantify the residues. In addition to acetonitrile, other solvents can be used for pesticide extraction, including ethyl acetate [22-25], which is more suitable for GC analysis than acetonitrile, as it is less polar and provides a smaller liquid-to-gas expansion volume [26]. In this study a method using QuEChERS extraction and GC-MS was developed for the analysis of two frequently applied pesticides in apple. The studied pesticides were representative of two of the most commonly used classes, e.g., carbamates (carbofuran) and organophosphorous (diazinon). The proposed method was validated according to European guidelines. In addition, the expanded uncertainty was evaluated taking into account the different sources of uncertainty that affect the process.

\section{EXPERIMENTAL}

Analysis of the pesticides was carried out on Agilent Technologies 7890A GC-MS instrument. In addition, the MS detector (Agilent Technologies 5975C VL MSD with tripleaxis detector, US 11398601), FID detector (Agilent Technologies 5188-5372 FID detector), pure water device (Millipore ultra pure water device, FONA81849), Mixer (Waring Commercial, 8010ES), Injector (Genject, 20002), analytical balance (Mettler Toledo JB1603 C/FACT with 10-4 sensitivity), centrifuge (Sigma 2-16 KC and Zentaifugen), homogenizer (IKA T 18 Basic Ultra-Turrax). The chemicals used are in the form of magnesium sulphate (Merck, 106067), acetic acid (Merck, 100063), acetonitrile (Merck, 1.00003) and Primer-Sekonder Amine (Thermoscientific, 60105-203). Pesticide standards were obtained from Sigma-Aldrich.

Ninety apple sample among harvested products in 2014 and kept in 6 different cold storage depot at 5 different time period in Karaman province, were collected according to random sampling method and they formed the material of research.

Preperation of standards: Certificated Sigma-Aldrich brand standards that their concetrations are clear, were used. Standard stock solutions of various concentrations were prepared in acetone and stored at $4{ }^{\circ} \mathrm{C}$ (purity $>95 \%$ ). From $1000 \mathrm{mg} /$ $\mathrm{kg}$ stock standards working standards that their concentration were indicated below, were prepared. Diazinon: 0.1, 0.5, 1.0, $1.5 \mu \mathrm{g} / \mathrm{kg}$; carbofuran: $0.1,0.5,1.0,1.5 \mathrm{mg} / \mathrm{kg}$ with acetonitrile were completed to $100 \mathrm{~mL}$. As an example calibration curve of diazinon standard is shown in Fig. 1.

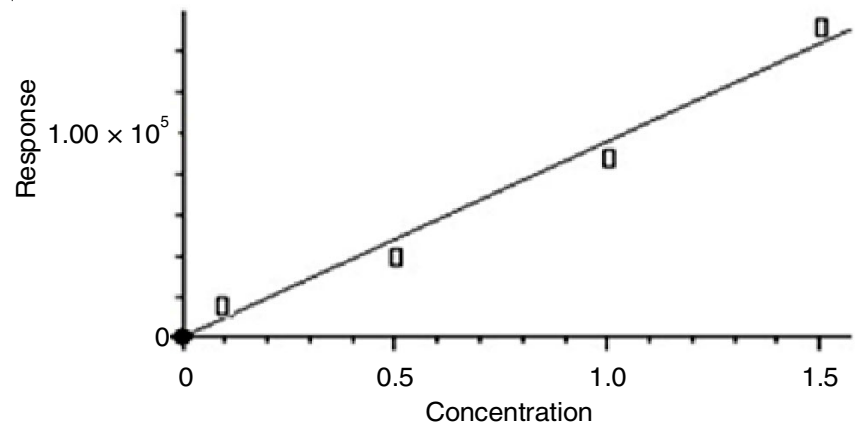

Fig. 1. Calibration curve of the diazinon standard $(\mu \mathrm{g} / \mathrm{kg})$ 
System conditions: GC-MS analysis was carried out using an Agilent 7890A GC system integrated with an Agilent G4513A series auto sampler and a 5975C VL mass selective detector (MSD). The analytes were separated a $30 \mathrm{~m} \times 0.25$ $\mathrm{mm} \times 0.25 \mu \mathrm{m}$ film thickness HP-5MS fused-silica capillary column. The injector was set at $250^{\circ} \mathrm{C}$ and the carrier gas was helium at a flow rate of $1 \mathrm{~mL} / \mathrm{min}$. The oven temperature was initially at $70{ }^{\circ} \mathrm{C}$ for $2 \mathrm{~min}$, increased at a rate of $40{ }^{\circ} \mathrm{C} \mathrm{min}-1$ upto $150{ }^{\circ} \mathrm{C}$; held for $4 \mathrm{~min}$; increased at a rate of $9{ }^{\circ} \mathrm{C} \mathrm{min}^{-1}$ up to $200^{\circ} \mathrm{C}$; increased at a rate of $24^{\circ} \mathrm{C} \mathrm{min}^{-1}$ up to $280{ }^{\circ} \mathrm{C}$ and held for $15 \mathrm{~min}$. The ion source, quadrupole and transfer line temperature were set at 230,150 and $280^{\circ} \mathrm{C}$, respectively. The mass spectrometer was operated at $70 \mathrm{eV}$ in electron impact (EI) mode. Solvent delay was $8 \mathrm{~min}$ and the injection volume was $1 \mathrm{~mL}$. The GC-FID analysis was performed using an Agilent 6850 series gas chromatograph equipped with a flame ionization detector. Separations were performed on a $30 \mathrm{~m} \times 0.25 \mathrm{~mm} \times 0.25 \mu \mathrm{m}$ film thickness HP-5MS fusedsilica capillary column. The injector and detector temperatures were $250{ }^{\circ} \mathrm{C}$ and $300{ }^{\circ} \mathrm{C}$, respectively. The injection port was operated at a 1:15 split. Flow rate of carrier gas nitrogen was set at $5.0 \mathrm{~mL} \mathrm{~min}^{-1}$. Total run time was $27.347 \mathrm{~min}$.

Preparation of examples to analysis: The samples taken from cold storage were brought to laboratory in transparent bags and kept in refrigerator at $+4{ }^{\circ} \mathrm{C}$ until analysis. Efficient amount was used from samples kept for analysis. Three apple samples were made homogeneous by grinding completely with mechanical grinders. The amounts for extraction were taken from these homogeneous samples by weighing.

Extraction: In extract of samples QuEChERS method that is widely used in pesticides analysis was used since it is fast, easy, cheap, effective, certain and reliable method [17]. $10 \mathrm{~g}$ were taken from samples grinded in $50 \mathrm{~mL}$ centifuge tubes and after adding $10 \mathrm{~mL}$ acetonitrile with $1 \%$ acidity, $4 \mathrm{~g} \mathrm{MgSO}_{4}$ and $1 \mathrm{~g}$ sodium acetate and were shaken by hand. Later the samples were centrifuged in a centrifuge working at $9000 \mathrm{rpm}$ for $2 \mathrm{~min} .2 \mathrm{~mL}$ of centrifuged samples were taken from upper phases and transferred to $30 \mathrm{~mL}$ glass tubes. $0.6 \mathrm{~g}$ $\mathrm{MgSO}_{4}$ and $0.2 \mathrm{~g} \mathrm{PSA}$ (primary secondary amine) was added. The samples were centrifuged at $5000 \mathrm{rpm}$ for $1 \mathrm{~min}$. Sufficient amounts from upper phases of centrifuged samples were taken and put into vials so solution ready to be analyzed in GC-MS and GC-FID equipment was obtained [20].

Method validation: The validation of the analytical method was performed by the following parameters: linearity, precision and limit of detection and limit of quantification. The method has been validated according to EC SANCO/10684/2009 directive [27]. The calibration curves of the compounds in the matrix were obtained by plotting the peak area against concentration of the corresponding calibration standards at four calibration levels between 0.1 and $1.5 \mathrm{mg} \mathrm{kg}^{-1}$. The limit of detection (LOD) and the limit of quantification (LOQ) were determined by considering the slope of the calibration curve and the residual standard deviation of the regression line, calculated with the equations described elsewhere [28].

\section{RESULTS AND DISCUSSION}

Carbofuran and diazinon, obtained from 90 samples from 6 different cold storages (Ayaz, Babaoðlu, Cavsa, Kirefe,
Yildizbas, Tasbas) randomly in Karaman province at 5 different time periods, in solutions obtained by QuEChERS method were measured by GC-MS equipment. According to the findings, pesticides residues were identified in most of 90 analyzed samples. GC-MS, GC-FID chromatograms and mass spectrums of carbofuran and diazinon standard are shown in Figs. 2-4. GC-MS chromatograms of the carbofuran and diazinon materials obtained in apple samples are shown in Fig. 5. Chromatographic parameters of carbofuran and diazinon materials are given in Table-2. The linearity data (equation, correlation coefficient, $\mathrm{R}^{2}$ ), LOD, LOQ are given in Table-3. Average values

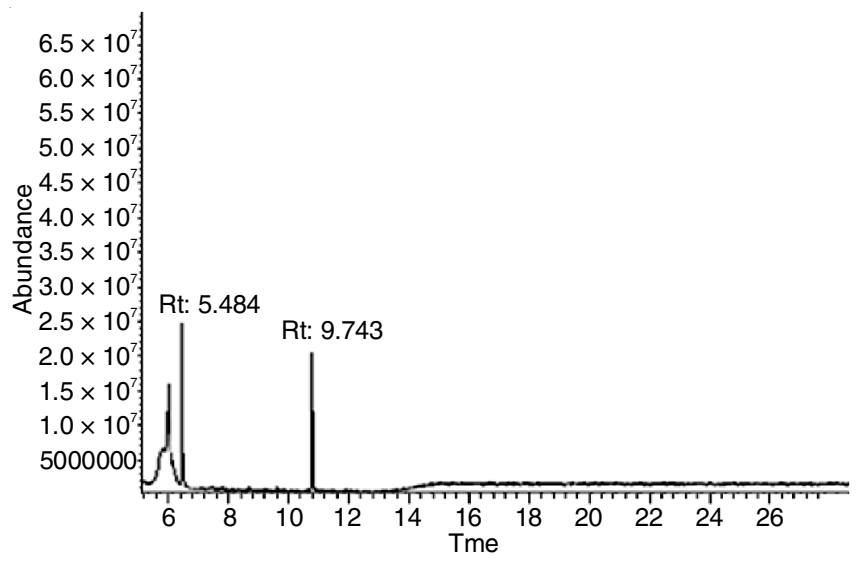

Fig. 2. GC-MS chromatogram of the carbofuran and diazinon standard (total ion current)

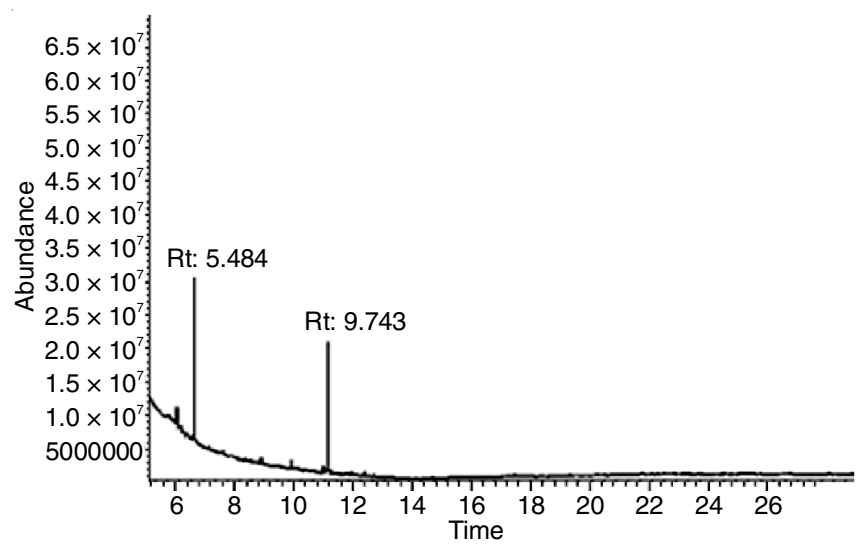

Fig. 3. GC-FID chromatography of the carbofuran and diazinon standard

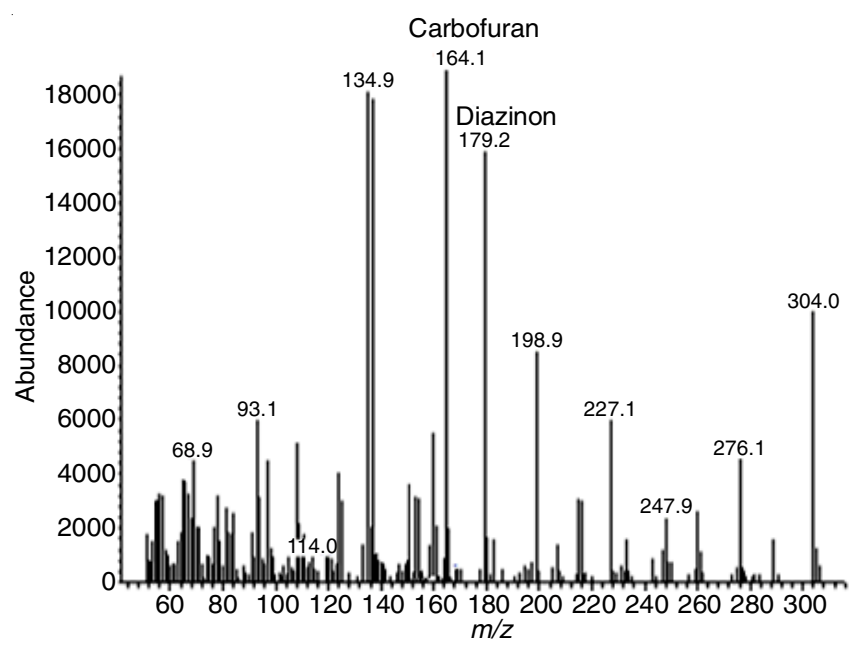

Fig. 4. GC-MS mass spectra of the carbofuran and diazinon standard 


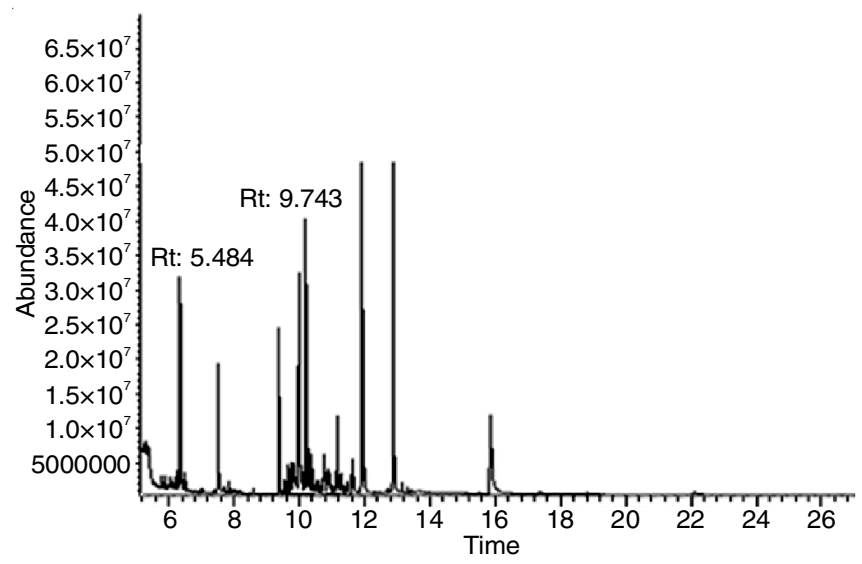

Fig. 5. GC-MS chromatogram of the carbofuran and diazinon material of the apple sample

\begin{tabular}{ccccc}
\hline \multicolumn{5}{c}{ TABLE-2 } \\
CHROMATOGRAPHIC PARAMETERS FOR THE \\
SELECTED COMPOUNDS ANALYZED BY GC-MS \\
\hline \multirow{2}{*}{ Pesticide } & m.f. & $\begin{array}{c}\text { m.w. } \\
(\mathrm{g} / \mathrm{mol})\end{array}$ & $\begin{array}{c}\text { Target } \\
\text { ion }(\mathrm{m} / \mathrm{z})\end{array}$ & $\begin{array}{c}\text { Retention } \\
\text { time }(\mathrm{min})\end{array}$ \\
\hline $\begin{array}{c}\text { Carbofuran } \\
\text { Diazinon }\end{array}$ & $\mathrm{C}_{12} \mathrm{H}_{15} \mathrm{NO}_{3}$ & 221.26 & 164.1 & 5.484 \\
$\mathrm{C}_{12} \mathrm{H}_{21} \mathrm{~N}_{2} \mathrm{O}_{3} \mathrm{PS}$ & 304.35 & 179.2 & 9.743 \\
\hline
\end{tabular}

of carbofuran and diazinon in apple samples taken from cold storage is given in Table-4. Graphics of average values are shown in Figs. 6 and 7.

The residue levels of diazonin and carbofuran in apple samples were determined. In order to identify medicine residues at least three apple samples that were chosen randomly, were homogenized by homogenizator. In extract of samples QuEChERS method was used since it is fast, easy, cheap, effective, certain

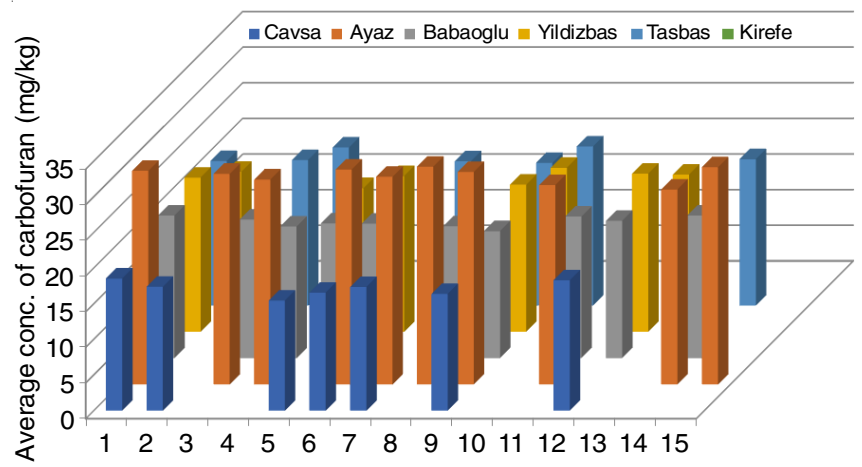

Fig. 6. Average amounts of carbofuran in the samples $(\mathrm{mg} / \mathrm{kg})$

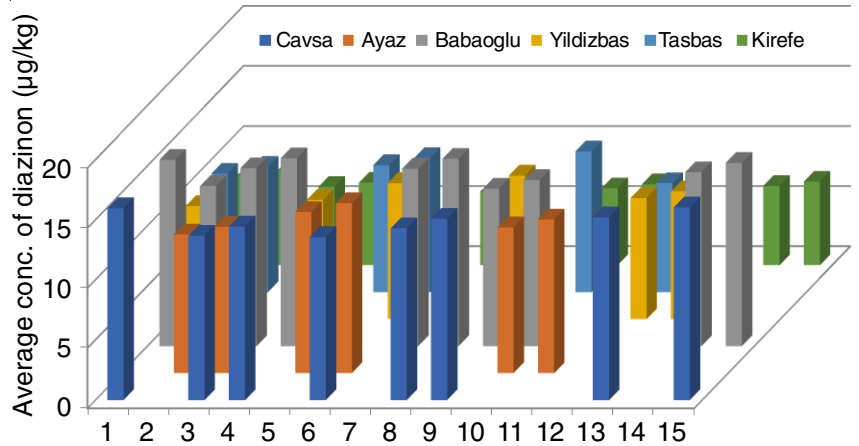

Fig. 7. Average amounts of diazinon in the samples $(\mu \mathrm{g} / \mathrm{kg})$

and reliable method. The residues of pesticides were taken from this homogenate with acetonitrile and given to GC-MS equipment in a suitable way. According to the results, the carbofuran and diazinon are forbidden in Turkey, were determined in large amounts of samples.

TABLE-3

LINEARITY DATA (EQUATION AND CORRELATION COEFFICIENT, R²), LIMIT OF DETECTION; LIMIT OF QUANTIFICATION

\begin{tabular}{cccccc}
\hline Pesticide & Linearity range & Regression equation & $\mathrm{R}^{2}$ & Limit of detection & Limit of quantification \\
\hline Carbofuran & $0.1-1.5 \mathrm{mg} / \mathrm{kg}$ & $\mathrm{y}=13011 \mathrm{x}+32579$ & 0.997 & $0.03 \mathrm{mg} / \mathrm{kg}$ & $0.10 \mathrm{mg} / \mathrm{kg}$ \\
Diazinon & $0.1-1.5 \mu \mathrm{g} / \mathrm{kg}$ & $\mathrm{y}=12775 \mathrm{x}+10251$ & 0.994 & $0.60 \mu \mathrm{g} / \mathrm{kg}$ & $1.70 \mu \mathrm{gg} / \mathrm{kg}$ \\
\hline
\end{tabular}

TABLE-4

AVERAGE AMOUNTS OF CARBOFURAN AND DIAZINON IN THE SAMPLES

\begin{tabular}{|c|c|c|c|c|c|c|c|c|c|c|c|c|}
\hline & \multicolumn{6}{|c|}{ Carbofuran (mg/kg) } & \multicolumn{6}{|c|}{ Diazinon $(\mu \mathrm{g} / \mathrm{kg})$} \\
\hline & Cavsa & Ayaz & Babaoglu & Yildizbas & Tasbas & Kirefe & Cavsa & Ayaz & Babaoglu & Yildizbas & Tasbas & Kirefe \\
\hline 1 & 18.54 & 29.98 & 20.02 & 21.64 & 20.28 & ND & 15.96 & ND* & 15.50 & 9.40 & 9.85 & 7.50 \\
\hline 2 & 17.40 & ND & ND & 22.46 & ND & ND & ND & 11.54 & 13.32 & ND & 10.42 & 7.92 \\
\hline 3 & ND & 29.56 & 19.44 & ND & 20.42 & ND & 13.68 & 12.18 & 14.80 & ND & ND & 6.50 \\
\hline 4 & ND & 28.76 & 18.48 & ND & 22.18 & ND & 14.44 & ND & 15.62 & 9.92 & ND & 6.86 \\
\hline 5 & 15.44 & ND & 18.9 & 20.18 & ND & ND & ND & 13.40 & ND & ND & 10.56 & $\mathrm{ND}$ \\
\hline 6 & 16.56 & 30.14 & 18.86 & 21.86 & ND & ND & 13.56 & 14.14 & ND & 11.32 & 11.14 & ND \\
\hline 7 & 17.36 & 29.14 & ND & ND & 20.24 & ND & ND & ND & 14.76 & ND & ND & 6.10 \\
\hline 8 & ND & 30.56 & 18.50 & ND & ND & ND & 14.30 & ND & 15.58 & ND & ND & 6.44 \\
\hline 9 & 16.40 & 29.80 & 17.82 & 20.66 & 20.02 & ND & 15.08 & ND & 13.10 & 11.94 & ND & ND \\
\hline 10 & ND & ND & ND & 23.02 & 22.32 & ND & ND & 12.12 & 13.82 & ND & 11.70 & 6.38 \\
\hline 11 & ND & 27.96 & 19.86 & ND & ND & ND & ND & 12.78 & ND & ND & ND & 6.72 \\
\hline 12 & 18.28 & ND & 19.26 & 22.20 & ND & ND & ND & ND & ND & 10.06 & 9.06 & ND \\
\hline 13 & ND & ND & ND & 22.06 & ND & ND & 15.20 & ND & ND & 10.62 & ND & ND \\
\hline 14 & ND & 27.34 & 20 & ND & 20.54 & ND & ND & ND & 14.46 & ND & ND & 6.58 \\
\hline 15 & ND & 30.48 & ND & ND & ND & ND & 16.04 & ND & 15.24 & ND & ND & 6.94 \\
\hline $\begin{array}{c}\text { Average } \\
\pm \text { SD }\end{array}$ & $\begin{array}{c}17.14 \pm \\
1.092\end{array}$ & $\begin{array}{c}29.37 \pm \\
1.073 \\
\end{array}$ & $\begin{array}{c}19.12 \pm \\
0.734\end{array}$ & $\begin{array}{c}21.76 \pm \\
0.933\end{array}$ & $\begin{array}{c}20.86 \pm \\
0.966\end{array}$ & ND & $\begin{array}{c}14.78 \pm \\
0.948\end{array}$ & $\begin{array}{c}12.69 \pm \\
0.951\end{array}$ & $\begin{array}{c}14.62 \pm \\
0.931\end{array}$ & $\begin{array}{c}10.54 \pm \\
0.948\end{array}$ & $\begin{array}{c}10.46 \pm \\
0.932\end{array}$ & $\begin{array}{c}6.795 \pm \\
0.549\end{array}$ \\
\hline
\end{tabular}

$\mathrm{ND}=$ None detection 


\section{Conclusion}

When studies in world wide are examined, voluminous quantity of pesticides are used to increase productivity. One of the most important reasons of pesticides usage is to struggle with plant mites in order to compansate food demand of increasing population. Also pesticides are used to lengthen shelf life of products. As all these are taken into consideration, producers continue pesticides usage until harvest season. That is why it is possible not to comply with waiting period of pesticides. Turkey has given serious importance to especially agriculture and stock breeding subjects during EU orientation period. Foremost among them innovations such as prescription system in agricultural medicines. Also with farmer provision system (CKS) big steps were taken in controlled production of producers. Consulting programmes given by agricultural engineers were supported and residual analyses were standardized routinely. The usage of 2 pesticides in apple (carbofuran and diazinon) examined in this research, are in prohibited pesticides list according to EU standards and Turkish Food Cortex Pesticides Maximum Residue Regulation. According to results finding prohibited pesticides in most of the apple samples show how important this study is in terms of human health. According to these results it is suggested that our farmers do not have sufficient knowledge about applying pesticides. Although agriculture has great place in economy of our country, Karaman province has an important place in exporting apple. Most of the apples harvested in Karaman are kept in cold storage depots in the province. The apples are both sold in the country and exported to mainly Arab countries, EU and Russia. In previous studies carbofuran and diazinon residues were obtained as a result of analysis in most of the apples in cold storage. Turkish Food Cortex Pesticides Maximum Residue Regulation was published in 2014. According to this, prohibited carbofuran and diazinon were identified in most of the samples. Pesticides usage should be done consciously and controlled in order to provide food security of our people and protect our environment and foreign trade. In EU and USA low risk or environmental friendly pesticides are given priority. However in Turkey environmental friendy pesticides are not given priority both in registration and supporting of consumptions. That is why, notably human health, precutions should be taken to prevent refusal of production exported to EU and Russia. In terms of protecting the health of our people, sometimes pesticides analysis of domestic products should be done as well as producers and tradesmen should be warned and raised awareness. Immediate precautions should be taken by government agencies about this subject.

\section{REFERENCES}

1. A. Beyer and M. Biziuk, Food Chem., 108, 669 (2008); https://doi.org/10.1016/j.foodchem.2007.11.024.

2. A. Kruve, A. Künnapas, K. Herodes and I. Leito, J. Chromatogr. A, 1187, 58 (2008); https://doi.org/10.1016/j.chroma.2008.01.077.

3. M. Tuzen, Food Chem. Toxicol., 47, 1785 (2009); https://doi.org/10.1016/j.fct.2009.04.029.

4. K. Wilkinson, W.P. Grant, L.E. Green, S. Hunter, M.J. Jeger, P. Lowe, G.F. Medley, P. Mills, J. Phillipson, G.M. Poppy and J. Waage, Philos. Trans. R. Soc. Lond. B. Biol. Sci., 366, 1933 (2011); https://doi.org/10.1098/rstb.2010.0415.
5. J.A. Fernandez, Contextual Role of TRLs and MRLs in Technology Management, Sandia National Laboratories, United States, DOE Contract No. AC04-94AL85000 (2010).

6. A. Ren, X. Qiu, L. Jin, J. Ma, Z. Li, L. Zhang, H. Zhu, R.H. Finnell and T. Zhu, Proc. Natl. Acad. Sci. USA, 108, 12770 (2011); https://doi.org/10.1073/pnas.1105209108.

7. A. Aguilera, A. Valverde, F. Camacho, M. Boulaid and L. García-Fuentes, Food Control, 35, 146 (2014); https://doi.org/10.1016/j.foodcont.2013.06.038.

8. Y. Han, W. Li, F. Dong, J. Xu, X. Liu, Y. Li, Z. Kong, X. Liang and Y. Zheng, Food Control, 31, 560 (2013); https://doi.org/10.1016/j.foodcont.2012.11.050.

9. O. López-Fernández, R. Rial-Otero and J. Simal-Gándara, Food Control, 34, 530 (2013); https://doi.org/10.1016/j.foodcont.2013.05.022.

10. Z. Kong, W. Shan, F. Dong, X. Liu, J. Xu, M. Li and Y. Zheng, Food Addit. Contam.: Part A, 29, 1280 (2012); https://doi.org/10.1080/19440049.2012.690347.

11. L. Martin, M. Mezcua, C. Ferrer, M.D. Gil Garcia, O. Malato and A.R. Fernandez-Alba, Food Addit. Contam.: Part A, 30, 466 (2013); https://doi.org/10.1080/19440049.2012.749541.

12. M.S. Turabi, Agricultural Medicine in the Republic of Turkey, Registration and Licensing System. In: Organic Farming and Organic Farming Conference, KTMMOB Agricultural Engineers Odasi, 9 (2004).

13. N. Delen, E. Durmusoglu, A. Guncan, N. Gungor, C. Turgut and A. Burcak, Problems Concerning Pesticide Use in Turkey, Residues and Reduced Sensitivity in Organisms. In Agricultural Engineering VI. Technical Congress, pp. 3-7 (2005).

14. M. Özdemir, F. Açkurt, M. Kaplan, M. Yildiz, M. Löker, T. Gürcan, G. Biringen, A. Okay and F.G. Seyhan, Food Chem., 73, 411 (2001); https://doi.org/10.1016/S0308-8146(00)00315-0.

15. A. Aksoy, Y.K. Das, O. Yavuz, D. Guvenc, E. Atmaca and S. Agaoglu, Bull. Environ. Contam. Toxicol., 87, 65 (2011) https://doi.org/10.1007/s00128-011-0286-Z.

16. A. Akyildiz, E. Agcam, S. Gurkan, B. Cetinkaya, E. Karaca and H. Benli, J. Agric. Sci., 20, 112 (2014).

17. W. Ahmad, A.A. Al-Sibaai, A.S. Bashammakh, H. Alwael and M.S. El-Shahawi, Trends Analyt. Chem., 72, 181 (2015); https://doi.org/10.1016/j.trac.2015.04.022.

18. M.A. Farajzadeh, S.M. Sorouraddin and M.R.A. Mogaddam, Mikrochim. Acta, 181, 829 (2014); https://doi.org/10.1007/s00604-013-1157-6.

19. N.S. Pano-Farias, S.G. Ceballos-Magaña, R. Muñiz-Valencia, J.M. Jurado, Á. Alcázar and I.A. Aguayo-Villarreal, Food Chem., 237, 30 (2017); https://doi.org/10.1016/j.foodchem.2017.05.030.

20. M. Anastassiades, S.J. Lehotay, D. Štajnbaher and F.J. Schenck, J. AOAC Int., 86, 412 (2003).

21. A. Melo, S.C. Cunha, C. Mansilha, A. Aguiar, O. Pinho and I.M. Ferreira, Food Chem., 135, 1071 (2012); https://doi.org/10.1016/j.foodchem.2012.05.112.

22. P. Aysal, A. Ambrus, S.J. Lehotay and A. Cannavan, J. Environ. Sci. Health $B, 42,481$ (2007); https://doi.org/10.1080/19312450701392490.

23. K. Banerjee, D.P. Oulkar, S. Dasgupta, S.B. Patil, S.H. Patil, R. Savant and P.G. Adsule, J. Chromatogr. A, 1173, 98 (2007); https://doi.org/10.1016/j.chroma.2007.10.013.

24. H. Berrada, M. Fernández, M.J. Ruiz, J.C. Moltó, J. Mañes and G. Font, Food Control, 21, 36 (2010); https://doi.org/10.1016/j.foodcont.2009.03.011.

25. H.G. Mol, A. Rooseboom, R. van Dam, M. Roding, K. Arondeus and S. Sunarto, Anal. Bioanal. Chem., 389, 1715 (2007); https://doi.org/10.1007/s00216-007-1357-1.

26. K. Mastovska and S.J. Lehotay, J. Chromatogr. A, 1040, 259 (2004); https://doi.org/10.1016/j.chroma.2004.04.017.

27. P. Bouwen, The European Commission. Lobbying the European Union: Institutions, Actors and Issues, pp. 19-38 (2009).

28. K.S. Miller and B. Ross, An Introduction to the Fractional Calculus and Fractional Differential Equations, Wiley, New York (1993). 